Submission to

\title{
QUALITATIVE RESEARCH IN SPORT AND EXERCISE
}

June 2011

Exercise, Service and Support:

Client experiences of Physical Activity Referral Schemes (PARS) 


\begin{abstract}
Physical Activity Referral Schemes (PARS) continue to represent one of the most prevalent interventions in the fight against chronic illness such as Coronary Heart Disease (CHD) and obesity. Despite this, issues surrounding low retention and adherence continue to hinder the potential effectiveness of such schemes on public health. This article reports on the second stage of a larger investigation into client experiences of PARS focussing specifically on findings from five client focus groups and interviews with five scheme organisers. The analysis reveals three main factors impacting on participants' perceptions of the quality of service and support at the scheme: the organisation of PARS provision, engagement with the PARS community, and the client support networks. The article demonstrates that staff have a considerable role to play in engaging clients in the PARS system and that scheme organisers should give serious thought to ensuring that clients have valuable and sustainable networks of support. Furthermore, it is suggested that scheme organisers need to facilitate a system in which staff are genuinely engaged with the needs of clients and are able to provide individualised programmes of physical activity.
\end{abstract}

\title{
Introduction
}

Evidence concerning the relationship between sedentary lifestyles and physical and mental health problems has become overwhelming (Giné-Garriga et al., 2009; Lee, Griffin and Simmons, 2009; Mertz, Lee, Sui, Powell and Blair 2010) and relates strongly to the dual importance physical activity exhibits as both a preventative aid and a therapeutic intervention (Biddle, Fox and Boucher, 2000; Ellis, Crone, Davey and Gorgan, 2007; Riddoch, PuigRibera and Cooper, 1998). Despite compelling evidence concerning the benefits to health that can be gained from physical activity, research consistently reports that up to $80 \%$ of the UK population may be insufficiently active to accrue such gains (Thurston and Green 2004). 
It is now widely accepted that physical activity at moderate intensity, five days per week, for 30 minutes, is the minimum to elicit meaningful health gains (NHS 2001).

\section{Physical Activity Referral Schemes (PARS)}

PARS are a systematic individualised process (Gidlow, Johnston, Crone and James, 2005) whereby a patient fitting a specific criteria is referred, by a medical professional (most commonly a GP), to an exercise centre. At that centre, the patient (now referred to as a client) is given a physical activity programme designed to facilitate and encourage life-long adherence (Leijon et al., 2010). In recent years there have been over 600 PARS schemes operating in the UK (Wright Foundation, 2005). The nationwide enthusiasm for PARS, coupled with the potential for improving public health, led to the publication of 'Exercise Referral Systems: A National Quality Assurance Framework' (NQAF) by the NHS in 2001. Once engaged with such a scheme, the client is assessed by an Exercise Professional (NHS, 2001). Hence, the role of the health care professional is not to dictate the frequency, intensity, duration or type of activity, but to refer the client to an Exercise Professional who then determines the precise nature of the physical activity to be undertaken (NHS, 2001).

There is no shortage of research to suggest that PARS are fundamentally beneficial; evidence abounds as to the potential impact of these services. PARS successfully increasing the levels of clients’ physical activity could cost just $£ 300$ per life saved (Harrison, Roberts and Elton, 2004), although Isaacs et al., (2007) suggest that PARS are not so cost effective. Despite this, Schutzer and Graves (2004) have underlined the potential cost benefit to the NHS by suggesting that increased physical activity would reduce future GP visits and lessen future client dependence on medication. Furthermore, Hillsdon, Foster, Cavill, Crombie and Naidoo (2005) suggest that referral to an exercise specialist leads to a longer-term change in clients' 
physical activity levels than does counselling by a health professional. PARS are widely seen as a short term health measure, the most common form comprising 12-15 physical activity sessions. Despite this, the philosophy behind PARS is devoted to life-long physical activity adherence. The health benefits of physical activity are transient (Warburton, Nicol and Bredin, 2006), thus anything but a concentration on the promotion of life-long physical activity adherence would be of little benefit to public health. Success, in terms of adherence to PARS has not been universally achieved. The vast majority of those referred drop-out within 12 months (Leijon et al., 2010). However, PARS have not been a universal failure with some schemes reporting sustained improvement in clients' physical activity levels and subsequent positive health indicators (NHS, 2001). Success across a number of specific schemes has also been reported (Seefeldt, Malina and Clark, 2002), although scepticism remains over changes in long term lifestyle habits (Riddoch et al. 1998; Morgan 2005). Despite attempts by the World Health Organisation [WHO] (2003) to define adherence, there is no consistency within PARS of how this concept is measured (Leijon et al., 2010). Some schemes consider retention as low as $20 \%$ to be successful (Cock, Adams, Ibbestson and Baugh, 2008). This not only makes comparison difficult, but further highlights the need for schemes to adopt accepted definitions of adherence. For the purposes of this article, we take the term 'adherence' to equate to a long-term maintenance of physical activity, whilst we use the term 'retention' to indicate continued attendance to a referral programme.

Difficulties with self-monitoring and improvement are compounded by the paucity of rigorous research into PARS (Leijon et al. 2010). The NICE (2006a; 2006b) reviews demanded that research should focus on demonstrating the long-term impact of PARS although, to date, this stipulation remains unheeded (James et al., 2008). Furthermore, schemes have been criticised for placing the emphasis of programmes inappropriately. 
Riddoch et al. (1998: 50) state “... it should be noted that the impact [of PARS] upon clients is consistently perceived to be at the social and psychological levels - whereas schemes are normally set up to impact upon physiological factors". There are many factors involved in explaining the poor adherence rates of some PARS (Giné-Garriga et al., 2009), contributing towards the formation of barriers that clients' perceive to prevent adherence to a physical activity programme.

\section{The Importance of Service Quality}

The NQAF proposes that PARS should be considered as a service (NHS, 2001). The vast majority of research focussing on PARS to date has failed to draw upon the extensive literature surrounding service provision, despite the acknowledgement that the critical importance of exceptional quality within the service industries is well established throughout the literature (Laroche, Ueltschy, Abe, Cleveland and Yannopoulos 2004). Kim and Kim (1998) highlight client perceptions of excellent service quality are crucial in order to attract new members and retaining existing clientele in the leisure industry; a trait not uncommon within other service industries (Park and Kim 2000; Triado, Aparico and Rimbau 1999). Perceptions of high service quality are critical to client retention (Newman 2001). It is this client perception of service quality as opposed to the industry's own understanding of the term that dictates customer up-take and adherence (Ko and Pastore 2004). Two other factors in the literature underline the critical nature of service quality to PARS; Desombre and Eccles (1998) concluded facility reputations and experiences of others were key factors in the decision-making process of which facility to patronise, underlining the importance of favourable word-of-mouth marketing. Furthermore, Donnelly and Shiu (1999) highlighted that expectations of clients are continually increasing and, therefore, assessments of client 
perceptions of service quality should be made regularly; a call that is upheld throughout the literature, not least because these expectations will evolve during contact with the service (Dawes and Rowley 1996). In addition, Newman (2001) highlights the importance of interrogating service quality in such a way as to enable change to the current system enhancing provision, not merely measuring and reporting. Whilst the quantitative measurement of service quality has been keenly contested for the last 20 years (Cock et al., 2008), the conceptual base of this concept, as defined by Parasuraman et al., (1985), to be the gap between client expectation and perception has been widely accepted and represents a core theoretical basis of this investigation. The upshot of this discussion suggests that problems surrounding retention and adherence within PARS maybe be tackled by identifying elements of the service which fail to live up to client expectations.

\section{Expertise, staffing and social support}

Client perceptions of scheme delivery and quality are inextricably linked to the availability and close supervision of staff (Williams, Hendry, France, Lewis and Wilkinson, 2007). Failure to provide quality supervision and support has been identified as an adherence barrier (French and Hainsworth, 2001; Stathi, McKenna and Fox, 2004; Williams et al., 2007). In turn, quality leadership and a prioritisation of the importance of PARS for clients have been cited as having an impact upon adherence (Bray et al. 2005; Loughead and Carron, 2004). The majority of research in this area has focused on class-based physical activity and has highlighted the link between quality staff support in terms of a positive physical activity environment and self-efficacy (Williams et al., 2007) and enjoyment (Crone, Smith and Gough2005). An integral part of providing staff support to participants is the emphasis 
placed on training (NHS, 2001). Both high and low adherers have reported the regularity of participation is dependent upon staff availability and support (Williams et al., 2007). This does not merely refer to the level of expertise within a particular field, but also the way in which members of the PARS are treated as individuals (French and Hainsworth, 2001). Engaging staff in expert training has been reported to increase scheme adherence rates (Buckley et al. 1999). The NQAF recognises the need for expertly trained staff and supported the formation of the Register of Exercise Professionals (REPS), which seeks to improve the competency and training for those within the health and fitness industry (REPS, 2010). The literature clearly advocates a professional approach by staff extending into courtesy, empathy and general helpfulness, all factors that are important in maintaining a quality service and, lowering barriers to physical activity adherence (Williams et al., 2007). Hence, the part that professional support plays in eliminating barriers to adherence is well established. Support from staff should be consistent and continuous; clients may need to hear a message repeatedly in order to affect behaviour (Isaacs et al., 2007). Clients who are regularly contacted by staff are more likely to maintain their participation (Hillsdon et al. 2005; Seefeldt et al. 2002). Likewise, long-term follow-up has been shown to be an effective method of improving adherence (Isaacs et al., 2007).

In addition, considerable value in the lowering and eliminating of barriers to physical activity adherence is also attributed to social support (Crone et al., 2005; Seefeldt et al. 2002; Stathi et al. 2004; Wiliams et al., 2007). In this sense, encouragement and affirmation from family members, peers and friends is considered vital to overcoming barriers to physical activity adherence (Coon and Coleman, 2004; Stathi et al., 2004), so too is support from GPs (Schutzer and Graves, 2004), staff members (Seefeldt et al., 2002), and fellow exercisers (Crone et al., 2005). Though not universally reported, the positive effects of social support 
have been reported to be more influential amongst older participants (McAuley et al., 2003) and especially elderly women (Litt, Kleppinger and Judge, 2002). Taylor (2003) suggests that social support processes should extend beyond the time-scale of the referral. However, others suggest that the most important phase with regards to social support is the initial period (Hardcastle and Taylor, 2001). Some family members, usually spouses, have occasionally been reported to be unsupportive of partners adopting a physical activity programme, to the extent that participants felt compelled to withdraw (Taylor, 1996).

\section{Context and Method}

This investigation embraces an interpretive perspective and is committed to understanding the perceptions and expectations of the participants. Tashakkori and Teddlie's (1998) proposition that individuals construct their own understandings of knowledge is adopted here. In acknowledging the importance of context and culture, this investigation seeks to explore the personal experiences of the participants and how these complex social interactions are interpreted. From a client perspective, this approach seeks to understand the 'gap' between expectation and perception and how this shapes their relationship with physical activity. Focus groups were selected as they represent an effective method for the exploration of understanding relating to physical activity programmes, being commonly used in this domain and also because they are an invaluable method for developing understanding surrounding service provision (Crone and Guy, 2008). From the perspective of the scheme organisers, this investigation seeks to understand how provision is constructed, given what has been presented as a particularly challenge and complex task; to deliver a medically-instigated referral in local authority leisure facilities (Cock et al., 2008). Given the 'expert' professional knowledge of the scheme organisers and the familiarity between these individuals and the lead research, 
semi-structured interviews represented the ideal method for the exploration of these concepts (Jones, 2004).

The findings presented here derive from research carried out between September 2002 and March 2003 with staff and clients from five PARSs, two of which were located in the South East of England and three in the North West ${ }^{1}$. The schemes were strategically selected to ensure a range of provision. Selection was based around the 'age', size (number of referrals), number of exercise centres, affluence of the surrounding area and the nature of activities (individual or group). Schemes were either managed by the local authority or by scheme coordinators at host leisure centres. At the time of the research, four of the five featured schemes had been operational for at least three years and were delivered across multiple sites (between two and five) at dedicated leisure facilities (i.e. sports centres). They varied in size from 30 to over 150 referrals per month, with a combined total of over 3000 clients per year. Three of the schemes offered both individual and group exercise sessions; two provided only individual referrals. Using data from the Office for National Statistics (2004), two of the schemes were drawn from areas of deprivation, two from affluent areas and one close to the national average. A two-stage methodological process was used to investigate the factors affecting retention rates in PARSs and to develop an understanding of service quality and adherence within this setting. The first stage featured the distribution of a service quality assessment instrument entitled REFERQUAL. ${ }^{2}$ The results of this, together with issues raised within the related literature, informed the second stage which comprised a series of client focus groups (comprising a total of 25 respondents) and one-to-one interviews with Scheme Organisers and exercise professionals. The empirical data featured here are taken from this

\footnotetext{
${ }^{1}$ In order to preserve anonymity, pseudonyms have been used throughout.

2 REFERQUAL is a bespoke adaptation of the SERVQUAL instrument (Parasuraman, Zeithaml and Berry, 1988) for evaluating service quality in PARS. Further details of this instrument including the study investigating the reliability of the tool can be found in Cock, Adams, Ibbetson and Baugh (2006).
} 
second stage of data collection. The absence of service quality assessment within the PARS settings to date underlines the originality of this methodology in terms of the generation of original findings. Ethical approval for the research was gained from the NHS North West Multi-Centre Research Ethics Committee (MREC).

At the outset, the intention was to randomly select PARS reflecting the upper and lower bounds of adherence rate performance. However, delay in the publication of the Wright Foundation's audit of UK schemes meant that no centrally collated register of PARSs existed in the early stages of this investigation, negating the possibility of stratified random selection. Furthermore, at the time of the research (and as is still the case) no accepted definition of 'adherence' had been established eliminating the possibility of selecting schemes by retention 'success' as none of the PARSs quantified the concept in the same way. Similarly, all five schemes operated differently in terms of the interaction between clients and staff. One scheme operated a one-to-one appointment-based referral which required the participants to book with a dedicated exercise professional. More typically, following the consultation with a trained exercise professional to establish a physical activity programme, the participants were largely responsible for deciding when to access the exercise facility. In some cases, this meant choosing an appealing group session such as aquarobics or pilates; occasionally these were led by an exercise professional directly linked to the PARS. More commonly, particularly at larger schemes spread over multiple sites, the physical activity programme comprised a range of typical exercises such as use of treadmills, rowing ergometers and resistance machines to be conducted in a fitness suite. In such cases, participants could choose when to attend the facility (although commonly 'off-peak') where the staff member on duty could be drawn from a wide range of staff in addition to the PARS team such as recreation assistants or gym instructors. 
One client focus group was conducted at each of the five research sites. Participants were selected at random from stratified groups comprising self-declared adherers and non-adherers, regardless of the stage of completion of the referral. These groups were constructed from those responding positively to a written request which all of the research subjects received as part of the consent forms which they completed prior to involvement. Focus group participation was confirmed by telephone and via follow-up confirmation letter and were led by the first author of this paper. Attendance at the focus groups ranged from between three and seven participants and discussion lasted between 60 and 75 minutes. Each focus group comprised a range of participants in terms of the stage of completion of their referral and the extent to which they had adhered. Whilst the selection of heterogeneous groups can lead to power imbalances and a lack of respect for opinions expressed by some members of the group (Robson, 2011), the potential of such approaches to add to the richness and depth of understanding surrounding the gaps between client expectation and perception was considered to outweigh such concerns. At the commencement of the focus groups, considerable stress was placed on the value of all clients, regardless of their stage of completion. To ensure an equal status, all group members were asked to introduce themselves and briefly describe their PARS story to date (Parker and Tritter, 2006); these contributions were uninterrupted and were well respected by all participants. The priority of the facilitator was to encourage discussion between participants, advocating reflection of others' ideas (Kritzinger, 2004) and to understand the group's construction of the expectationperception gaps. Participants were invited to discuss their experiences around a range of topics including the PARS facilities, the reliability and responsiveness of the service received, the interaction with scheme staff, and their relationship with physical activity. One semistructured interview was conducted at each research site with the Scheme Organiser or with 
an exercise professional depending on the operational responsibilities within each scheme. Each interview lasted between 60-75 minutes. By the time that interviews were conducted regular contact had been established with all five schemes and a significant degree of familiarity had accrued with both operational procedures and PARS staff.

From the data analysis a series of key themes emerged relating to the way in which clients perceived the quality of service offered by the respective schemes and some of the potential barriers to participation and retention. These data also provide evidence regarding staff views of service provision. We present these themes by way of three broad categories which encompass the key issues around which respondent views were structured. These themes comprise: (i) the organisation of PARS provision, (ii) the motivational aspects of scheme adherence, and (iii) the client support networks. ${ }^{3}$

\section{The organisation of PARS provision}

The organisational aspects of PARS provision proved to be a central issue for respondents in terms of adherence and retention irrespective of age or medical condition. In-depth analyses of the focus group data revealed that certain aspects of scheme organisation were particularly problematic, one of which was the flexibility and timetabling of PARS sessions for clients required to attend at a particular time and the conflict that this caused with wider respondent commitments. Employment, for example, was a case in point:

I found that the quality and the flexibility of the women ... did vary, some of them were extremely helpful, and accommodating, but I did find that the timings were very rigid ... which doesn't always help, if you're working. I work four days a week ... so often I had to come back in the evening which wasn't particularly convenient ... (Abigail) 
Abigail's comments imply an expectation to be able to schedule her exercise programme conveniently in relation to outstanding commitments. Abigail's perception concurs with the findings of French and Hainsworth (2001) who suggest that flexibility of staff and timetabling is appreciated by clients in PARS settings, and clearly support Taylor's (1999) assertion that full time employment is a barrier to exercise adherence. Scheme organisers and exercise professionals were generally aware of this issue but appeared constrained in terms of the scheduling of classes. The difficulty in providing regular and reliable 'out-of-hours' services was highlighted by scheme organisers pointing to the often casual employment patterns of exercise referral staff and the changeability of staff rotas; an issue noted by Julie:

We don't display the rotas or anything like that for our customers, because practically we couldn't do that. No way. Because it changes so frequently. We'd be constantly changing it.

The inconsistency of information with regard to the scheduling of sessions was raised in several of the focus groups and underlines the importance of the availability of accurate timetabling information, particularly for those constrained by occupational or transport/mobility issues (Seefeldt et al. 2002). Furthermore, an inconsistency of information was demonstrated across individual centres, conflicting with client expectation. Pauline explained:

The first time I went [to the PARS], I said what I was there for and she [the Scheme Organiser] just looked at me with this blank expression as if to say 'You're talking alien. I've no idea what you're talking about. I've never heard of this group'. I said 'Well, it's not a band, it's a group of heart surgery patients which are coming to exercise'.

Discussion within focus groups supported this assertion with some clients regarding the withdrawal of the availability of organised sessions negatively and others questioning the

\footnotetext{
${ }^{3}$ Whilst recognising the dangers of essentialising respondent accounts, we have chosen to present our analysis in this way because these were the predominant themes which emerged from the qualitative data collection process.
} 
referral process more generally. Here Brenda provides insight into the difficulties which she experienced when trying to establish contact with her Scheme Organiser:

Well even this morning I tried to ring [the PARS] and, eventually, the phone said, 'We're finishing this call because the Receptionist isn't available'. So, I ... drove up there and spoke to them and the Receptionist said 'I was probably busy, so I wasn't able to take the phone'. So, that's not always helpful either because I did try to contact somebody to speak to them and they said: 'Oh, there's no-one there at the moment ... you'll have to come back when there's somebody there'.

Geraldine encountered similar problems and, because of this, had clearly become disillusioned in terms of scheme attendance:

She'd [the Scheme Organiser] write to me and I could never get hold of her on the phone. I never knew where she was ... So, I wrote back to her saying 'I can't get you on the phone, I've dropped out of the swimming because the water is too cold and I'm not really doing anything now'. And then I never heard anything from her; she didn't contact me again.

Geraldine's comments lie in stark contrast to those reported by O'Sullivan et al., (2010) whose participants' relayed wholly positive communication with a physical activity counsellor. Geraldine's frustrations underline O'Sullivan et al.'s (2010) conclusions that participants need to be able to access long-term, individualised counselling by a trained and experienced exercise professional. A further problem in relation to organisational issues and, in particular, client confidence, was that of staff competence. The majority of focus group participants attributed this lack of confidence to the inability of the exercise professionals to be able to differentiate between the various medical conditions from which clients' suffered, a point clearly articulated by James:

I don't think they inspire confidence ... You go and obviously you feel a little bit vulnerable ... or you're a bit concerned and these people don't seem to be able to answer the questions ... I wouldn't trust them - one of those

In turn, these categories allow us to demonstrate more fully potential barriers to PARS adherence. 
people that I met anyway - I wouldn't trust them to tell me what to do and know that I wasn't damaging my body.

One of the problems here was that participants were largely unsure of the level and extent of qualifications held by Scheme Organisers and instructors; however, a number of clients did allude to having a clear sense of the hierarchical status of those with whom they came into contact during the course of the referral process. This issue was put to Scheme Organisers and, as discussion with Jill revealed, on the whole, those in her position were well aware of these difficulties:

The people who sit down and do the initial consultation ... have the recognised qualification levels to do the induction process. I feel that the potential weakness ... is the ones that they actually go and exercise side by side with, whether it's in the gym facility or whether it's in an over 50s class or a chair-based mobility work or in the pool for an aquability session ... and yes, I could possibly agree with the lack of specific knowledge. On the flipside of that, there has to be a balance between the medical model and the non-medical community. This is a management, it's not treatment ... it's definitely a non-medical model that we're going down.

Scheme Organisers and Exercise Professionals were largely in agreement that the medical community had a responsibility to be involved in the promotion and dissemination of information about staff in order to give credence to staff competence:

The clients that come to me, I expect the hospital to have explained who they're coming to next and where they're going. Either from that or from the GP they should trust that they're being referred to somebody who knows what they're talking about. (Sandeep)

These client and scheme organiser comments demonstrate the magnitude of the gap between client expectation of the closeness and expertise of supervision contrasted with perception of the service. The failure to offer staff support which clients perceive to be of sufficient quality is supportive of those findings of Stathi et al., (2004) and Williams et al., (2007), although this context provides an extra dimension. James' vulnerability further exposes the difficulties 
in providing a service focussed on behaviour management, whilst dealing with clients expecting support from staff who are sufficiently knowledgeable to deal with their medical condition. Jill's comments do little to address these concerns.

Further discussions with Scheme Organisers confirmed the importance of this issue and the potential an exercise partnering scheme could have on improving adherence with several participants relating to previous experiences of such policies in hospital settings. Yet, staff competence and scheme availability were only one small part of client negativity towards PARS. More important were the broader motivational aspects of scheme participation and it is to these that we now turn.

\section{Engagement with the PARS community}

A central issue raised by focus group participants in relation to PARS adherence was that of engagement with the scheme; that is, the extent to which the operationalisation of schemes facilitated a desire within them to consistently attend scheduled sessions. Whilst, as we have seen, certain organisational factors militated against sustained attendance, respondents expressed a general level of understanding towards complexity of the referral process and the pressures under which exercise professionals were operating. That said, the visibility of staff and the extent to which they demonstrated an individual knowledge and genuine interest in clients' capabilities, was of key importance to many (see also Taylor, 1996). Indeed, it was clear from interviews with Scheme Organisers that there was a recognition amongst staff that this was the case, as Graham pointed out: 
I'm at every session so I think that helps in terms of the motivation of support that is there ... I know that the gym here is well staffed and there has always got to be one member of staff in the gym, and that's what [this] gym has decided on what they want to do. They're quite good and they [the clients] get help here, because if they're stuck on the programme and there's nobody in the gym to help them, they' $\mathrm{d}$ just give up in the end ... but at [Site 1] and [Site 3], they don't have to have somebody in the gym at all times, so they could go for the full hour session and they might never see a member of staff.

These thoughts demonstrate an appreciation of the need to address client expectation in terms of the regularity (Williams et al., 2007) and individualisation of staff support (French and Hainsworth, 2001). Stuart confirmed this view alluding specifically to client anxieties over exercise environments and the possible medical consequences in play:

I think ... [a lack of staff visibility] is a big de-motivator, especially if they're not sure of what they're doing, if their heart rate's going up and they're a bit like 'there's nobody there'.

That did not mean to say that visibility was everything. On the contrary, even when staff were visible, participants did not always regard their presence in a positive light. Here Jane and David respectively articulate serious reservations about their own experiences of PARS:

They sit around talking, they're reading the paper ... there are people going on equipment and using it wrong and never being shown how to use it correctly ... It's just a complete and utter waste of time. (Jane)

I just thought a couple [of the Exercise Professionals] were too young. 16/17 is too young. They haven't gained the experience ... At one point, with all due respect to young people, there's a 16 year old kid there that really didn't know what was going on. So that was it for me, I gave it up. (David)

Jane and David's comments are illustrative of the impact of the gap between client expectation and perception, revealing that disparity can lead to a disengagement with the service and, ultimately, to drop-out. Scheme Organisers acknowledged that inexperienced 
recreation assistants as young as 16 may work in the fitness suites, although denied that such individuals would be solely responsible for those environments. Nonetheless, clients' perceptions of inexperience appear to undermine their confidence in the system. The most common words cited by clients when responding to questions concerning their personal experiences of scheme attendance were 'attentive', 'individual' and 'interested', highlighting the importance of such qualities amongst support staff. Clients having suffered some form of cardiac disease were, (as one might imagine), particularly keen to receive attentive and visible support. Ray, Jean and Sheila were especially keen to make thier feelings known on this matter:

Being a 'cardy' [cardiac rehabilitation patient], I thought at least somebody should at least be here, monitoring what we're doing. (Ray)

They could, well, collapse I suppose, and it's a frightening feeling. If you're in the gym and somebody collapsed, and there is no-one around to help. (Jean)

I felt very much that after the 20 weeks, you're on your own. I wanted to ask a question; 'I've got this problem; what should I do?' 'Should I carry on?' But no-one could answer me. They're either too busy or they didn't want to know. (Sheila)

This issues are again illustrative of Williams et al.'s, (2007) and Isaacs et al.'s, (2007) findings surrounding the consistency and visibility of staff support, but add the extra dimension of how a failure to demonstrate an authentic interest in clients can contribute to a disengagement with the service. Exercise professionals acknowledged the need to individualise client care in this respect but one of their number, Gary, was quick to point out the benefits which cardiac rehabilitation patients brought with them especially with regard to a familiarity with exercise regimes and a stronger sense of ownership and dependence in terms of engagement with the ERS community: 
They [clients] maybe need more motivation, if they've never exercised in their life, and it's something new to them and they might need that motivation of somebody being there all the time pushing them on ... I find that the cardiac rehab clients are a lot better when it comes to that, because they've come from the hospital where they've done their Phase $3^{4}$ they've already got into the routine of exercise, they understand what they're meant to be doing, they understand what level they're working at. (Gary)

Likewise, Scheme Organisers were aware that a sustained and individualised approach to client care was an essential part of the referral process, yet as Julia noted, it was one which was often at issue:

Once a person's come in for a consultation, it's the continued contact and support during the 10 week programme and we have been aware that from our perception point of view, we see somebody at week one, then we hope that they respond to their evaluation appointment letter at week 10. But we have very little resources and time built into our current process for any further contact in the middle and we feel that that has had a detrimental affect on the adherence rates within the course.

Confirming the impact of staff interest and engagement at an individualised level, numerous focus group participants cited specific members of staff as being the main reason for adhering to a particular scheme. In turn, participants who dropped out cited the removal of certain staff members as the primary reason for this. In this sense, staff familiarity with the medical conditions and personal limitations of clients appeared to contribute to a heightened level of comfort and security amongst focus group members and to positive perceptions of individualised care.

\section{Client support networks}

The organisation and scheduling of PARS and the level of interest and engagement demonstrated by staff towards individual clients formed just part of a much wider network of

\footnotetext{
${ }^{4}$ Phase 3 refers to the third stage of Cardiac Rehabilitation which comprises structured physical activity programming under medical supervision. When patients 'graduate' from Phase 3, they often attend PARS as
} 
support which participants expected to have been in place as a constituent element of the referral process. Moreover, there was also a feeling amongst some focus group members that such support should permeate outside of the bounds of the exercise environment in order that sustained attendance might be encouraged, which reflects Taylor's (2003) findings concerning the importance of longevity of staff contact.. For example, several participants indicated a conscious desire to be contacted Scheme Organisers not only to provide the spur to attend, but also for purposes of reassurance:

I felt if somebody had rung me at that point I would have gone then ... Somebody rang me way after the scheme had finished and that was good because you think 'Oh well, they still were looking after me' ... I wish they would contact you even if it's only a few weeks that you haven't been. (Annie)

In addition to this, focus group discussion demonstrated that a failure on the part of Scheme Organisers to contact participants who looked likely to drop out might have a negative impact on client self confidence. In the following extract, Margaret emphasises the perception of a lack of regular contact with regard to personal confidence levels:

I've found that [not being contacted] has undermined my confidence because although I desperately want to go back and exercise, I'm thinking 'Well, maybe they think I'm too old to do all this? Maybe they think we've got so many people here, that we don't want another one, if you drop out, you drop out'. So it's undermined my confidence to some extent. For some of us it doesn't take a lot.

Gary (Exercise Professional) acknowledged the effectiveness of such policies:

When we were doing it [contacting non-attendees], it was really quite surprising. You'd phone them up and find out what's gone on with them and they'd often reappear. Having said that, the people that disappear in the first place will soon disappear again. But at least you'll still get a proportion of those back into the system.

Phase 4 of their treatment and rehabilitation. 
Circumstances such as those highlighted by Gary indicate that although a more personal and holistic approach to client need may be a part of bridging the gap in service quality, it is not necessarily a cure for drop out; such sentiments are broadly supportive of the related literature (Crone et al., 2005; Seefeldt et al. 2002; Stathi et al. 2004; Wiliams et al., 2007). However, one support strategy which clearly impacted client experience was that of social integration with other service users. Such strategies were not evident across all research sites but where it did feature respondents spoke enthusiastically about its benefits. Here, for example, Helen explains the advantages of meeting a fellow 'beginner' on her first visit to the hospital gym:

I was referred to the hospital gym, which I was quite frightened about because I'd never faced a gym in my life, but luckily they had an introduction afternoon, so you met the group. There was just one other lady there and we got on fine and that made a lot of difference because we sort of linked up and said 'We'll see you at the start of the gym', and that was quite a help. I progressed very well there ... eventually we were referred here [to another site], but I found it was very alien to me, because you went in, and it was very on your own ... I'd have preferred it we had a group ... I never saw this girl again, which was the highlight of my going to the other gym really, because we sort of related to each other ... I don't think I'd look forward to going back ... unless it was more of a group thing.

Helen's perceptions reflect those reported by Litt et al., (2002) relating the importance of social support for older women. At a general level, participants felt that social integration alleviated feelings of 'intimidation' and 'loneliness'; two common terms used within focus group discussions. Participants also felt that social interaction provided a much more appealing motivation for attending the scheme than exercise alone or even the activity itself. Few participants referred to actual physical activity as being the most enjoyable part of their experience, however the social aspects of referral seemed to help in this respect, as Harry noted: 
In a masochistic sort of way, I've come to enjoy the scheme. There's quite a camaraderie amongst the group, we've got into the second session up in the gym bit and sort of enjoy it.

Equally beneficial for some was the involvement in exercise programmes of experienced patients who came along to guide and assist during sessions and to provide encouragement and reassurance along the way. Moreover, Graham considered exercise partnering a potential method for creating accountability:

If you're going along with someone or someone is expecting you, you've got that commitment that just pushes you, it's like ... 'I don't really want to go, I feel shy on my own, but I said I'd go'.

Such sentiment was endorsed by Scheme Organisers who spoke of the benefits of mentoring arrangements amongst patients especially in terms of the way in which this might reduce the logistical burden on staff. Countering this was the risk that such practices posed. Indeed, Scheme Organisers were also acutely aware of potential liability issues relating to clients being 'instructed' by under/un-qualified personnel.

\section{Concluding remarks}

Our intention within this paper has been to consider client experiences of PARS and, in particular, to explore potential barriers to participation and adherence. In so doing, we began by outlining some of the logistical matters which might impinge upon client adherence, such as the organisation and availability of schemes, and issues concerning timetabling and communication which, when poorly managed, might serve to enhance the gap between participant expectation and perception. The findings we have presented offer a radically different perspective on client expectation and perception than has been frequently reported elsewhere (e.g. Crone et al., 2005; Crone, Johnston, Gidlow, Henley and James, 2008; 
O'Sullivan et al., 2010; Stathi et al., 2004). Our findings demonstrate that client perceptions of professional competence may constitute an inherent problem for PARS; that is, clients appear to draw confidence from both the procedures and knowledge of the wider medical community and, to this end, it is imperative that Scheme Organisers (and those who work with them) maintain a professional approach to their work in order to provide on-going reassurances to a client group who frequently encounter a sense of anxiety and vulnerability as a consequence of their medical conditions and circumstances. These findings extend the related literature (e.g. Crone et al., 2005, Isaacs et al., 2007 and Williams et al., 2007) concerning the nature of the relationship between staff and clients, forcing such professionals to seriously re-consider the importance of client expectation and perception in terms of their competence, experience and professionalism.

Our findings also establish client self confidence to be at the heart of adherence and retention and emphasise the importance of staff interaction, availability, enthusiasm and personal interest in terms of enhancing client perceptions of service quality. The clients featured here gained confidence through being regularly contacted by staff and by gaining a sense that Scheme Organisers were attentive to their individual needs. That said, reductions in client self confidence (and increased perceptions of staff disinterestedness) sit somewhat understandably alongside Scheme Organisers' attempts to juggle adherence issues within the context of acute under-resourcing. Whilst previous research has highlighted the importance and longevity of staff contacts (Hillsdon et al., 2005; Seefeldt et al., 2002), the authentic and personal dimensions discussed here demonstrate an innovative insight into the participants' perceptions of service quality. The 're-offending' of participants in relation to the cessation of exercise may well justify the withdrawal of such time consuming practices. Initial consultations were generally regarded positively by both clients and staff. However, the subsequent withdrawal 
of visual, attentive, and individual support was perceived negatively by participants, thus confirming previous research findings surrounding the relationship between exercise leader behaviour and client satisfaction (Loughead and Carron, 2004; O'Sullivan et al., 2010).

Our findings relating to the end of the referral process and the subsequent withdrawal of staff support will require Scheme Organsiers to reconsider how this element of the PARS system operates due to the strong, negative perception of clients revealing a substantial gap in service quality. Scheme Organisers were aware of some transitional issues but were unable to fund enough staff positions to meet client expectation in this regard. In addition, clients desired differing types and levels of support; some expecting to be 'led' through the referral process, others happy merely to seek help when necessary. Our findings extend those of Leijon et al., (2010) in relation to the creation of independent exercisers, by suggesting that one practical and realistic solution to client adherence may lie in the creation of broader, more personal and longer-term networks of support. The challenge for PARS, in this respect, is the establishment of such networks amidst the pressures of financial and operational constraint, alongside the balancing of the client expectation of a medical intervention with the behaviour management-based capabilities of exercise centre staff. This study has demonstrated that one way to accommodate support structures of this nature is to facilitate and encourage the involvement of family, friends, and fellow clients in PARS activity. 


\section{References}

Bandura, A. (1986), Social Foundations of Thought and Action: A Social-Cognitive Theory, Englewood Cliffs: Prentice-Hall.

Biddle, S. J., Fox, K., and Boutcher, S. (2000), Physical Activity and Mental Health: A National Consensus, London: Routledge.

Boyd, M. P., Weinmann, C., and Yin, Z. (2002), 'The Relationship of Physical SelfPerceptions and Goal Orientations to Intrinsic Motivation for Exercise', Journal of Sport Behaviour, 25, (1), pp. 1-18.

Bray, S. R., Millen, J. A., Eidsness, J., and Leuzinger, C. (2005), 'The Effects of Leadership Style and Exercise Program Choreography on Enjoyment and Intentions to Exercise', Psychology of Sport and Exercise, 6, pp. 415-425.

Buckley, J., Holmes, J., and Mapp, G. (1999), 'Exercise on Prescription, Cardiovascular Activity for Health', Oxford: Butterworth-Heinemann.

Campbell, P. G., MacAuley, D., McCrum, E., and Evans, A. (2001), 'Age Differences in the Motivating Factors for Exercise', Journal of Sport and Exercise Psychology, 23, pp. 191-199.

Cock, D., Adams, I. C., Ibbetson, A. B., and Baugh, P. (2006), 'REFERQUAL: A Pilot Study of a New Service Quality Assessment Instrument in the GP Exercise Referral Scheme Setting', BMC Health Services Research, 6, (61), pp. 1-6.

Cock, D., Adams, I. C., Ibbetson, A. B., and Baugh, P. (2008) 'The impact of the physical leisure environment on client adherence'. In Gilchrist, P. and Wheaton, B. (eds) Whatever Happened to the Leisure Society? Theory, debate and policy. Eastbourne: Leisure Studies Association. pp. 47-72.

Coon, S. K., and Coleman, E. A. (2004), 'Keep Moving: Patients with Myeloma Talk About Exercise and Fatigue, Oncology Nursing Forum, 31, (6), pp. 1127-1135.

Crone, D., and Guy, H. (2008) "I know it is only exercise, but to me it is something that keeps me going': A qualitative approach to understanding mental health service users' experiences of sports therapy', International Journal of Mental Health Nursing, 17, pp. 197-207.

Crone, D., Johnston, L. H., Gidlow, C., Henley, C., and James, D. (2008) 'Uptake and participation in physical activity referral schemes in the UK: An investigation of patients referred with mental health problems, Issues in Mental Health Nursing, 29, pp. 1088-1097.

Crone, D., Smith, A., Gough, B. (2005) 'I feel totally at one, totally alive and totally happy': a psycho-social explanation of the physical activity and mental health relationship' Health Education Research, 20, (5), pp. 600-611. 
Dawes, J., and Rowley, J. (1996), 'The Waiting Experience: Towards Service Quality in the Leisure Industry', International Journal of Contemporary Hospitality Management, $\mathbf{8}$, (1), pp. 16-21.

Desombre, T., and Eccles, G. (1998), 'Improving Service Quality in Trust Hospitals: Lessons From The Hotel Sector', International Journal of Health Care Quality Assurance, 11, (1), pp. 21-27.

Donnelly, M., and Shiu, E. (1999), 'Assessing Service Quality and its Link with Value for Money in a UK Local Authority's Housing Repairs Service Using the SERVQUAL Approach', Total Quality Management, 10, (4 and 5), pp. S498-S506.

Ellis, N., Crone, D., Davey, R. C., and Grogan, S. (2007) 'Exercise interventions as a therapy for psychosis: A critical review. British Journal of Clinical Psychology, 47, (1), pp. 95-111.

French, D., and Hainsworth, J. (2001), “There Aren't any Buses and the Swimming Pool is Always Cold!': Obstacles and Opportunities for the Provision of Sport for Disabled People', Managing Leisure, 6, pp. 35-49.

Gidlow, C., Johnston, L. H., Crone, D., and James, D. V. B. (2005) 'Attendance of exercise referral schemes in the UK: A systematic review', Health Education Journal, 64, (2), pp. 168-186.

Giné-Garriga, M., Martin, C., Martin, C., Puig-Ribera, A., Antón, J. J., Guiu, A., Cascos, A., and Ramos, R. (2009), 'Referral from primary care to a physical activity programme establishing long-term adherence? A randomized controlled trial. Rationale and study design. BMC Public Health, 9, (31).

Guillot, J., Kilpatrick, M., Hebert, E., and Hollander, D. (2004), 'Applying the Transtheoretical Model to Exercise Adherence in Clinical Settings', American Journal of Health Studies, 19, (1), pp. 1-10.

Hardcastle, S., and Taylor, A. H. (2001), 'Looking For More than Weight Loss and Fitness Gain: Psychosocial Dimensions Among Older Women in a Primary Care ExerciseReferral Program', Journal of Ageing and Physical Activity, 9, pp. 313-328.

Hardcastle, S., and Taylor, A. H. (2005), 'Finding an Exercise Identity in an Older Body: "It's Redefining Yourself and Working Out Who You Are"', Psychology of Sport and Exercise, 6, pp. 173-188.

Harrison, R. A., Roberts, C., and Elton, P. (2004), 'Does Primary Care Referral to an Exercise Programme Increase Physical Activity 1 Year Later? A Randomized Controlled Trial', Journal of Public Health, 27, (1), pp. 25-32.

Hillsdon, M., Foster, C., Cavill, N., Crombie, H., and Naidoo, B. (2005), The Effectiveness of Public Health Interventions for Increasing Physical Activity Among Adults: A Review of Reviews, (2 ${ }^{\text {nd }}$ edn.), London: Health Development Agency. 
Isaacs, A. J., Critchley, J. A., See Tai, S., Buckingham, K., Westley, D., Harridge, S. D. R., Smith, C., and Gottlieb, J. M. (2007) 'Exercise Evaluation Randomised Trial (EXERT): a randomised trial comparing GP referral for leisure centre-based exercise, community-based walking and advice only'. Health Technology Assessment, 11, (10).

James, D. V. B., Johnston, L. H., Crone, D., Sidford, A. H., Gidlow, C., Morris, C., and Foster, C. (2008) 'Factors associated with physical activity referral uptake and participation', Journal of Sports Sciences, 26, (2), pp. 217-224.

Jones, S. (2004) 'Depth interviewing' in C. Seale (Ed.) Social Research Methods: A reader, (pp. 257-260), London: Routledge.

Kim, C., and Kim, S. Y. (1998), 'Segmentation of Sport Centre Members in Seoul Based on Attitudes Toward Service Quality', Journal of Sport Management, 12, pp. 273-287.

Kitzinger, J. (2004) 'The methodology of focus groups: The importance of interaction between research participants', IN C. Seale (Ed.), Social Research Methods: A Reader, London: Routledge, pp. 269-272.

Ko, Y. J., and Pastore, D. L. (2004), 'Current Issues and Conceptualisations of Service Quality in the Recreation Sport Industry', Sport Marketing Quarterly, 13, pp. 158-166.

Laroche, M., Ueltschy, L. C., Abe, S., Cleveland, M., and Yannopoulos, P. (2004), 'Service Quality Perceptions and Customer Satisfaction: Evaluating the Role of Culture', Journal of International Marketing, 12, (3), pp. 58-85.

Lee, A. S. W., Griffin, S. J., Simmons, R. K. (2009), 'An evaluation of the effectiveness of 'Active for Life': An exercise referral scheme in West Suffolk', Public Health, 123, pp. 670-672.

Leijon, M. E., Bendtsen, P., Ståhle, A., Ekberg, K., Festin, K., and Nilsen, P. (2010) 'Factors associated with patients self-reported adherence to prescribed physical activity in routine primary health care', BMC Family Practice, 11, (38).

Litt, M. D., Kleppinger, A., and Judge, J. O. (2002), 'Initiation and Maintenance of Exercise Behaviour in Older Women: Predictors from the Social Learning Model, Journal of Behavioural Medicine, 25, pp. 83-97.

Loughead, T. M., and Carron, A. V. (2004), 'The Mediating Role of Cohesion in the Leader Behaviour-Satisfaction Relationship', Psychology of Sport and Exercise, 5, pp. 355371.

Loughead, T. M., Colman, M. M., and Carron, A. V. (2001), 'Investigating the Mediational Relationship of Leadership Class Cohesion, and Adherence in an Exercise Setting', Small Group Research, 32, pp. 558-575.

McAuley, E., Jerome, G. J., Elavsky, S., Marquez, D. X., and Ramsey, S. N. (2003), 'Predicting Long-Term Maintenance of Physical Activity in Older Adults, Predictive Medicine, 37, pp. 110-118. 
McKenna, J., and Vernon, M. (2004) 'How general practitioners promote 'lifestyle' physical activity'. Patient Education and Counseling 54, (1), pp. 101-106.

Mertz, K. J., Lee, D-C., Sui, X., Powell, K. E., Blair, S. N. (2010) 'Falls among adults: The association of cardiorespiratory fitness and physical activity with walking-related falls, American Journal of Preventive Medicine, 39, (1), pp. 15-24.

Morey, M. C., Dubbert, P. M., Doyle, M. E., MacAller, H., Crowley, G. M., Kuchibhatla, M., Schenkman, M., and Horner, R. D. (2003), 'From Supervised to Unsupervised Exercise: Factors Associated with Exercise Adherence', Journal of Aging and Physical Activity, 11, pp. 351-368.

Morgan, O. (2005), 'Approaches to Increase Physical Activity: Reviewing the Evidence for Exercise-Referral Schemes', Public Health, 119, pp. 361-370.

National Health Service (2001) Exercise Referral Systems: A National Quality Assurance Framework, London: National Health Service.

National Institute for Health and Clinical Excellence (2006a), Four Commonly Used Methods to Increase Physical Activity: Brief Interventions in Primary Care, Exercise Referral Schemes, Pedometers and Community-Based Exercise Programmes for Walking and Cycling, London: National Health Service.

National Institute for Health and Clinical Excellence (2006b), A Rapid Review of the Effectiveness of Exercise Referral Schemes to Promote Physical Activity in Adults, London: National Health Service.

Newman, K. (2001), 'Interrogating SERVQUAL: A Critical Assessment of Service Quality Measurement in a High Street Retail Bank', International Journal of Bank Marketing, 19, (3), pp. 126-139.

Office for National Statistics (2004), Neighbourhood Statistics, Visited: $23^{\text {rd }}$ April 2004, Last Modified: $23^{\text {rd }} \quad$ April 2004, http://neighbourhood.statistics.gov.uk/dissemination/home.do?bhcp=1.

O’Sullivan, T. L., Fortier, M. S,. Faubert, C., Culver, D., Blanchard, C., Reid, R., and Hogg, W. E. (2010), 'Interdisciplinary physical activity counseling in primary care: A qualitative inquiry of the patient experience', Journal of Health Psychology, 15, (3), pp. 362-372.

Parasuraman, A., Zeithaml, V. A., and Berry, L. L. (1985), 'A Conceptual Model of Service Quality and its Implications for Future Research', Journal of Marketing, 49, (4), pp. 41-50.

Parasuraman, A., Zeithaml, V. A., and Berry, L. L. (1988), 'SERVQUAL: A Multiple-Item Scale for Measuring Consumer Perceptions of Service Quality', Journal of Retailing, 64, (1), pp. 12-40. 
Park, S., and Kim, Y. (2000), 'Conceptualising and Measuring the Attitudinal Loyalty Construct in Recreational Sport Contexts', Journal of Sport Management, 14, pp. 197207.

Parker, A., and Tritter, J. (2006), 'Focus group method and methodology: current practice and recent debate', International Journal of Research and Method in Education, 29, (1), pp. 23-37.

Register of Exercise Professionals (2010), The Register of Exercise Professionals (REPs), Visited: $20^{\text {th }} \quad$ July 2010, Last Modified: $22^{\text {nd }}$ June 2010 , http://www.exerciseregister.org/REPsWhatis.html

Riddoch, C., Puig-Ribera, A., and Cooper, A. (1998) Effectiveness of Physical Activity Promotion Schemes in Primary Care: A Review, London: Health Education Authority.

Robson, C. (2011) Real World Research, ( $3^{\text {rd }}$ Edn.), Chichester: Wiley.

Schutzer, K. A., and Graves, S. (2004), 'Barriers and Motivations to Exercise in Older Adults', Preventive Medicine, 39, pp. 1056-1061

Seefeldt, V., Malina, R. M., and Clark, M. A. (2002), 'Factors Affecting Levels of Physical Activity in Adults', Sports Medicine, 32, (3), pp. 143-168.

Stathi, A., McKenna, J., and Fox, K. R. (2004), 'The Experiences of Older People Participating in Exercise Referral Schemes', Journal of the Royal Society for the Promotion of Health, 124, (1), pp. 18-23.

Tashakkori, A. and Teddlie, C. (1998) Mixed Methodology: Combining qualitative and quantitative approaches, London: Sage.

Taylor, A. H. (1996), Evaluating GP Exercise Referral Schemes: Findings from a Randomised Controlled Study, Chelsea School Research Centre, Topic Report 6, University of Brighton.

Taylor, A. H. (2003), 'The Role of Primary Care in Promoting Physical Activity', In McKenna, J., and Riddoch, C. (eds.), Perspectives on Health and Exercise, Basingstoke: Palgrave MacMillan, pp. 153-180.

Taylor, A. H., Doust, J., and Webborn, N. (1998), 'Randomised Controlled Trial to Examine the Effects of a GP Exercise Referral Programme in Hailsham, East Sussex, on Modifiable Coronary Heart Disease Risk Factors', Journal of Epidemiology and Community Health, 52, (9), pp. 595-601.

Thompson, P. D., Buchner, D., Piña, I. L., Balady, G. J., Williams, M. A., Marcus, B. H., Berra, K., Blair, S., Costa, F., Franklin, B., Fletcher, G. F., Gordon, N. F., Pate, R, R., Rodriguez, B. L., Yancey, A. K., and Wenger, N. K., (2003) 'Exercise and Physical Activity in the Prevention and Treatment of Atherosclerotic Cardiovascular Disease: A Statement From the Council on Clinical Cardiology (Subcommittee on Exercise, Rehabilitation, and Prevention) and the Council on Nutrition, Physical Activity, and 
Metabolism (Subcommittee on Physical Activity), Circulation, 107, (24), pp. 31093116 .

Thurston, M., and Green, K. (2004), 'Adherence to Exercise in Later Life: How Can Exercise on Prescription Programmes be Made More Effective?', Health Promotion International, 19, (3), pp. 379-387.

Triado, X. M., Aparico, P., and Rimbau, E. (1999), 'Identification of Factors of Customer Satisfaction in Municipal Sport Centres in Barcelona: Some Suggestions for Satisfaction Improvement', Cyber-Journal of Sport Marketing, 3, pp. 1-11.

Warburton, D. E. R., Nicol, C. W., and Bredin, S. S. D., (2006) 'Health benefits of physical activity: the evidence', Canadian Medical Association Journal, 174, (6), pp. 801-809.

Williams, N. H., Hendry, M., France, B., Lewis, R., and Wilkinson, C., (2007) 'Effectiveness of exercise-referral schemes to promote physical activity in adults: systematic review', British Journal of General Practice, (57), 545, pp. 979-986.

World Health Organisation (2003) Adherence to long-term therapies: evidence for action. Geneva: World Health Organisation.

Wright Foundation (2005) How Many Exercise Referral Schemes are there in the UK? Preliminary Survey, Visited: $18^{\text {th }}$ November 2005, Last Modified: $18^{\text {th }}$ November 2005, http://www.wrightfoundation.com/uk_research_study.htm.

\section{Word length: 9,284}

